\title{
Detection of small quantities of iodine
}

\section{M.L. Thorel}

To cite this article: M.L. Thorel (1849) Detection of small quantities of iodine, Philosophical Magazine Series 3, 35:237, 395-395, DOI: 10.1080/14786444908562710

To link to this article: http://dx.doi.org/10.1080/14786444908562710

册 Published online: 30 Apr 2009.

Submit your article to this journal

Џ Article views: 2

Q View related articles $₫$ 
3rd. Lastly, the third process, which is that proposed by M. Fehling, is based on the following fact: when a mixture of an alkaline chloride and bromide is perfectly precipitated by nitrate of silver, the first portions of the precipitate contain all the bromine which the solution contained.

This process, therefore, admits of concentrating the bromine, and employing such a quantity of nitrate of silver as is insufficient to precipitate the whole of the chlorine; and as the object is merely that of obtaining a compound of bromide and chloride very rich in bromide, the first process becomes readily applicable without any risk of serious error.

The silver precipitate ought to be well washed, and in order to decompose it by chlorine, it is to be fused, a quantity being introduced into a tube with a bulb, which is to be heated by a spirit-lamp. - Journ. de Pharm. et de Chim., Septembre, 1849.

\section{DETECTION OF SMALL QUANTITIES OF IODINE. BY M. L. THOREL.}

The method employed by the author for this purpose is the following, and is merely a modified method of using starch. Put into a small vial fifty or sixty grammes of the suspected liquor, or if it be a solid body, diffuse it in a small quantity of water; add six drops of pure nitric acid, and the same quantity of hydrochloric acid; a small piece of paper is then to be covered with a rather liquid preparation of starch and placed at the mouth of the vial, which is to be heated. If the liquor contains iodine, either in the state of iodide or iodate, the paper will assume a violet blue of greater or less intensity. The nitric acid sets the iodine free by decomposing the iodides, if any exist; the effect of the hydrochloric acid is, that it is substituted for the iodine, by decomposing the iodate, if it should be present.

If the paper should not become coloured at the moment of ebullition, the same quantity of the two acids should be added, shaking the vial strongly. In an instant, the spots should appear, and the stratum of iodine will gradually increase. It must not be immediately concluded that no iodine is present if no colour appears, for it is separated with difficulty from certain budies, as happens with molasses. In such cases a second operation must be performed, adding to the liquor ten to twenty centigrammes of tartrate of potash dissolved in a small proportion of water. Heat is to be applied an instant before the addition of the acids, which on this occrsion may be used in the proportion of eight to ten drops of nitric acid, and four drops of hydrochloric acid. After this trial an opinion may be arrived at with great certainty.

By operating in this manner, the presence of iodine may be detected in a mixture which contains only three to four milligrammes. With a mixture of twenty milligrammes of iodine and 200 grammes of salt, very intense spots may be obtained,-Journ. de Chém. Méd., Septembre 1849. 